\title{
Whisker Reinforced Glass Ceramic
}

\author{
Project \# DE-FG01-94CE15599 \\ Quarterly Progress Report \#3 \\ for the Period \\ March 28, 1995 - June 27,1995
}

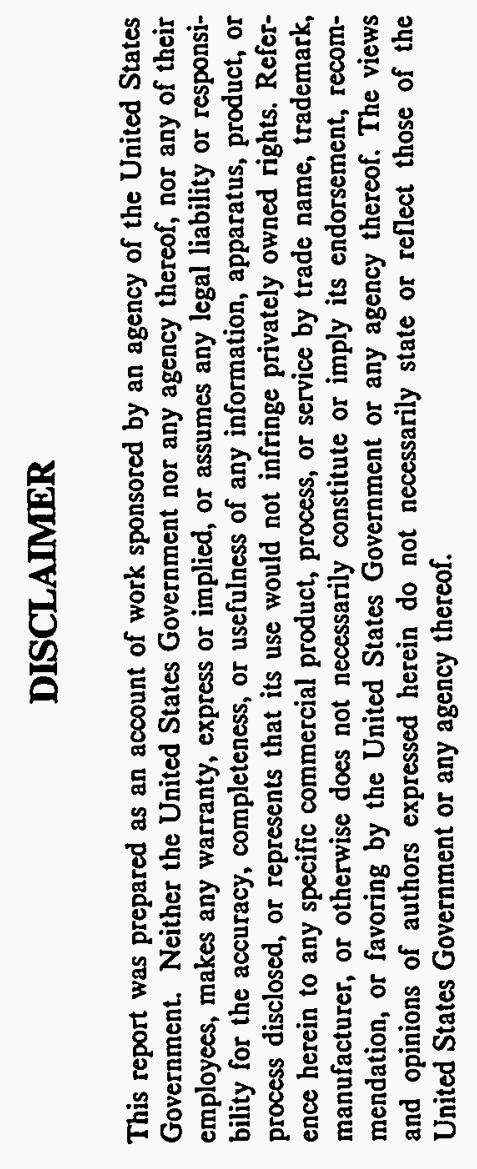

\author{
Prepared by \\ G.R. Pickrell and J.J. Brown, Jr. \\ Materials Technologies of Virginia \\ 1872 Pratt Drive \\ Blacksburg, Virginia 24060 \\ (703) 231-5082 (f) 231-3327 \\ Prepared for \\ U.S. Department of Energy \\ Office of Scientific and Technical Information \\ P.O. Box 62 \\ Oak Ridge, TN 37830
}

July 25, 1995 


\section{DISCLAIMER}

Portions of this document may be illegible in electronic image products. Images are produced from the best available original document. 


\section{objective/scope}

The goal of this project is to investigate the physical properties of an in-situ whisker reinforced glass ceramic material and to produce prototype heat exchanger tubes for testing in a coal combustion environment. The in-situ whisker reinforced glass ceramic process was developed and patented at Virginia Tech and licensed to MATVA. Successful completion of this project will demonstrate the potential for this new material to replace existing heat exchanger materials due to its superior chemical and physical properties.

\section{Technical Progress}

\section{Glass Melting, Cast Bar and Powder Preparation}

Several melts of the modified $B$-eucryptite were prepared and cast into stainless steel molds. The glass was melted at $1620^{\circ} \mathrm{C}$ for $3 \mathrm{hr}$ in fireclay crucibles (using an outer crucible lined with alumina powder for protection). After this period of time, the crucible was removed from the furnace and the glass poured into a stainless steel mold with internal cavity dimensions of approximately 0.5 in $x 4$ in $x 3$ in. The poured glass sample was allowed to cool in the stainless steel mold overnight. During the cooling period, the sample shattered into many large chunks. This process was attempted several times, but without satisfactory results.

Several other methods were attempted to keep the glass bars from shattering including preheating the molds to approximately $100^{\circ} \mathrm{C}$. Unfortunately, none of the methods attempted produced a viable way to prepare the glass bars in the metal mold without significantly modifying the chemical composition.

Examination of the pieces of the glass bars showed that there were a large number of tiny gaseous inclusions. These gaseous inclusions suggested that the fining of the glass had been insufficient.

One strategy to help reduce the number of these gaseous inclusions is to raise the melting temperature or increase the length of the melting time. Unfortunately, the fireclay crucibles which were used softened significantly during the $1620^{\circ} \mathrm{C} / 3 \mathrm{hr}$ firing as shown in Figure 1. The crucible on the right became oval shaped when grabbed by the glass tongs during removal All crucibles had to be removed by grasping the outer porcelain crucible. Therefore, increasing the melting temperature or length of heating time was not a viable option.

Another method to reduce the number of these gaseous inclusions is to add a small amount of a fining agent to the melt. Arsenic, sodium sulfate, sodium nitrate, sodium chloride, etc., are common additions to help control seeds in commercial glass melting operations. Sodium chloride was added to the $B$-eucryptite glass melt to try to aid fining. The glass bars made with this salt still shattered, but had a much lower number of seeds present (almost seed free). 
The shattering problem was presumed to be caused by the residual stresses which were developed during the rapid cooling of the glass in the metal molds. Preheating the metal molds to $100^{\circ} \mathrm{C}$ was not enough to reduce the thermal shock sufficiently. In an attempt to alleviate this problem, a refractory mold was prepared. This was accomplished by making a cavity in a refractory brick approximately lin. $x$ 1in. $x$ 6in. The glass was melted according to the same schedule listed above and poured into the refractory mold. Some outgassing of the refractory occurred producing large inclusions in the bottom surface of the bars. Also, the glass penetrated to a small extent into the large pores present in the refractory. This made removal of the bar impossible without destroying the refractory mold.

In order to alleviate these problems, the refractory, was lined with a fine alumina powder such that it filled all of the large pores in the refractory and formed a relatively flat surface. This was accomplished by mixing the alumina powder with acetone and forming a paste. The paste was then applied to the refractory in a fashion similar to puttying walls. The paste was allowed to air dry (in some cases the bricks were placed in a drying oven). After air dying the alumina powder coating remained adherent to the sides of the refractory brick well enough to allow pouring of the glass melt into the mold. Zirconia powder was also used in a similar fashion to the alumina powder. Both seemed to perform equally well. Several bars were poured using this procedure.

Bars made with this method remained intact after removal from the molds. During the cooling process in the refractory brick, the samples changed from a clear glass to an opaque bluish white material indicating that crystallization of the glass was occurring. There were still a large number of gaseous inclusions present on the surface of the bar samples. These samples were subsequently heat treated at $740^{\circ} \mathrm{C}$ for $2 \mathrm{hr}$ and $1040^{\circ} \mathrm{C}$ for $6 \mathrm{hr}$. Some of the samples prepared in this manner were ground using 60 grit silicon carbide sand paper on a polishing wheel with a water feed. This was done in order to determine if the bubbles which were present were located only on the surface or were present throughout the piece as well. The photograph of such a sample is shown in Figure 2. along with an "as cast" bar. The samples contained a large number of external pores located primarily on the bottom surface and only a small number of internal pores. This suggests that the source of these bubbles is from the refractory material and not from the glass itself. None of the samples prepared by this method were of sufficient homogeneity and density as to be suitable for mechanical property testing.

Another method to prepare bar samples for the mechanical property testing utilized the glass melt $\left(1620^{\circ} \mathrm{C}\right.$ for $\left.3 \mathrm{hr}\right)$ which was cooled at the maximum furnace rate in the refractory crucible. After cooling, the material (which was opaque and was at least partially crystallized) was removed from the fireclay crucible and ball milled to -325 mesh. This powder was mixed with appropriate amounts of binder and water and dry pressed into bars. The bars were sintered at $1200^{\circ} \mathrm{C}$ for $24 \mathrm{hr}$. A photograph of the resulting bars is shown if Figure 3 . 


\section{Comparison of Quenched versus Unquenched Material}

In order to compare samples made from translucent glass fragments with those made from opaque fragments (above), samples were also prepared by pouring the glass melt into water to quench. The clean glass fragments which were obtained were ball milled to -325 mesh and were dry pressed under the same conditions as above. The SEM micrographs of the fracture surfaces of the two types of samples mentioned above are shown in Figure 4. As can be seen in these micrographs, the morphologies of the fracture surfaces appear to be quite similar.

Density measurements (using Archimedes method) reveal that the densities of these two type of samples are also very similar. The average densities were $2.20 \mathrm{~g} / \mathrm{cc}$ for the bars made from the quenched glass powder and $2.30 \mathrm{~g} / \mathrm{cc}$ for the bars made from the slow cooled (opaque) material. These values were obtained on pieces broken from the two different types of bars.

In order to determine if there were any differences in the phases which were formed as a result of the different heat treatment schedules, samples of each type of bar were ground and $\mathrm{x}$-rayed. X-ray diffraction analysis of the powder ground from pieces of both types of samples reveals that there is no significant difference between the phases present in each of these samples. The phases formed in each samples were B-eucryptite and a small amount of rutile.

Since there were no significant differences between the morphology, density or phases present between the bars made from the glass melt quenched into water and the glass melt which was slow cooled, the slow cooled glass melt powder will be used to prepare the bar samples for the mechanical property characterization.

\section{Preparation of Bar Samples for Mechanical Property} Testing

Approximately ten melts of the B-eucryptite material have been prepared and allowed to cool at the maximum furnace cooling rate. These melts have been ball milled to -325 mesh. Fifty five of the 100 bars required for mechanical property testing have been prepared thus far. Samples of these bars are shown in Figure 2. The remaining 45 bars will be completed by the next reporting period.

Experiments are currently being conducted to determine if the 12 in. $x$ in. diameter heat exchanger tubes can be made by siip casting the $B$-eucryptite material in plaster of paris molds. Small cylindrical test molds have been prepared and will be used to slip cast small cylinders and tubes. This will allow determination of whether it is feasible to prepare the larger diameter tubes by this method. These experiments will be completed for the next reporting period. 

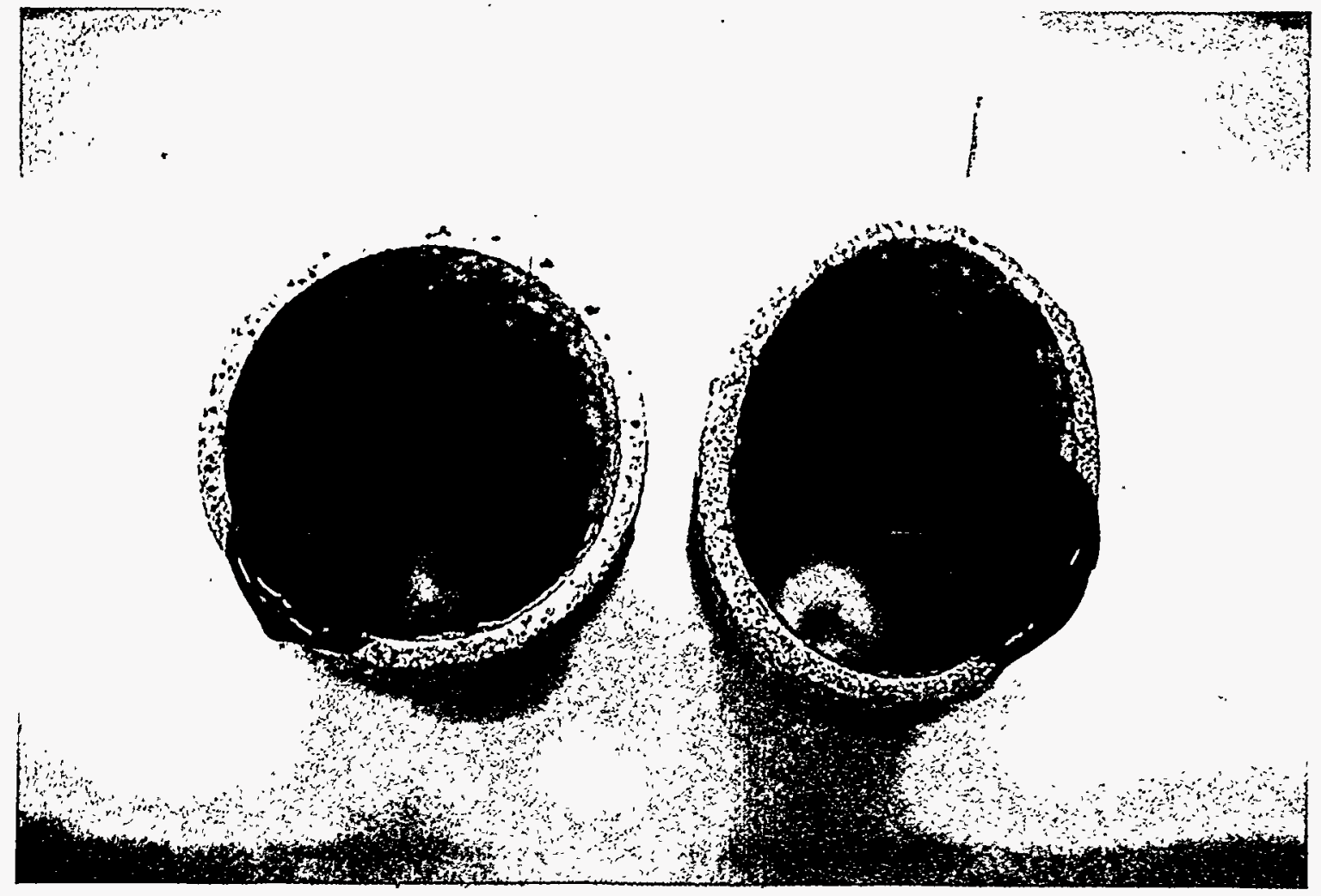

Figure 1. Refractory crucibles after glass melting

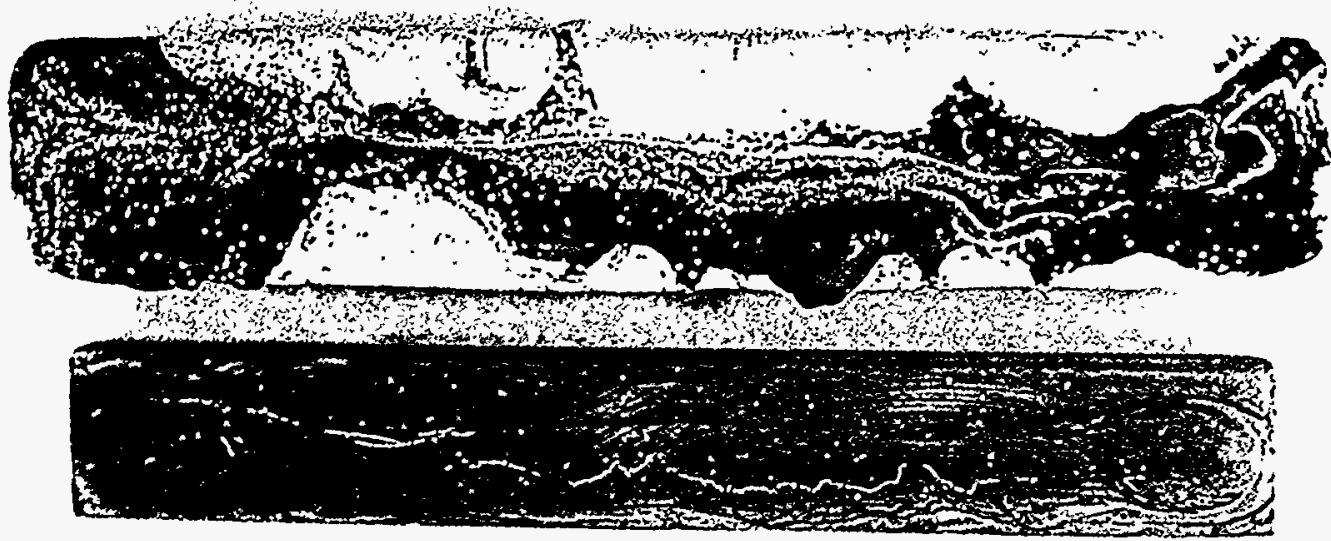

Figure 2. Glass melt cast into refractory bar molds 


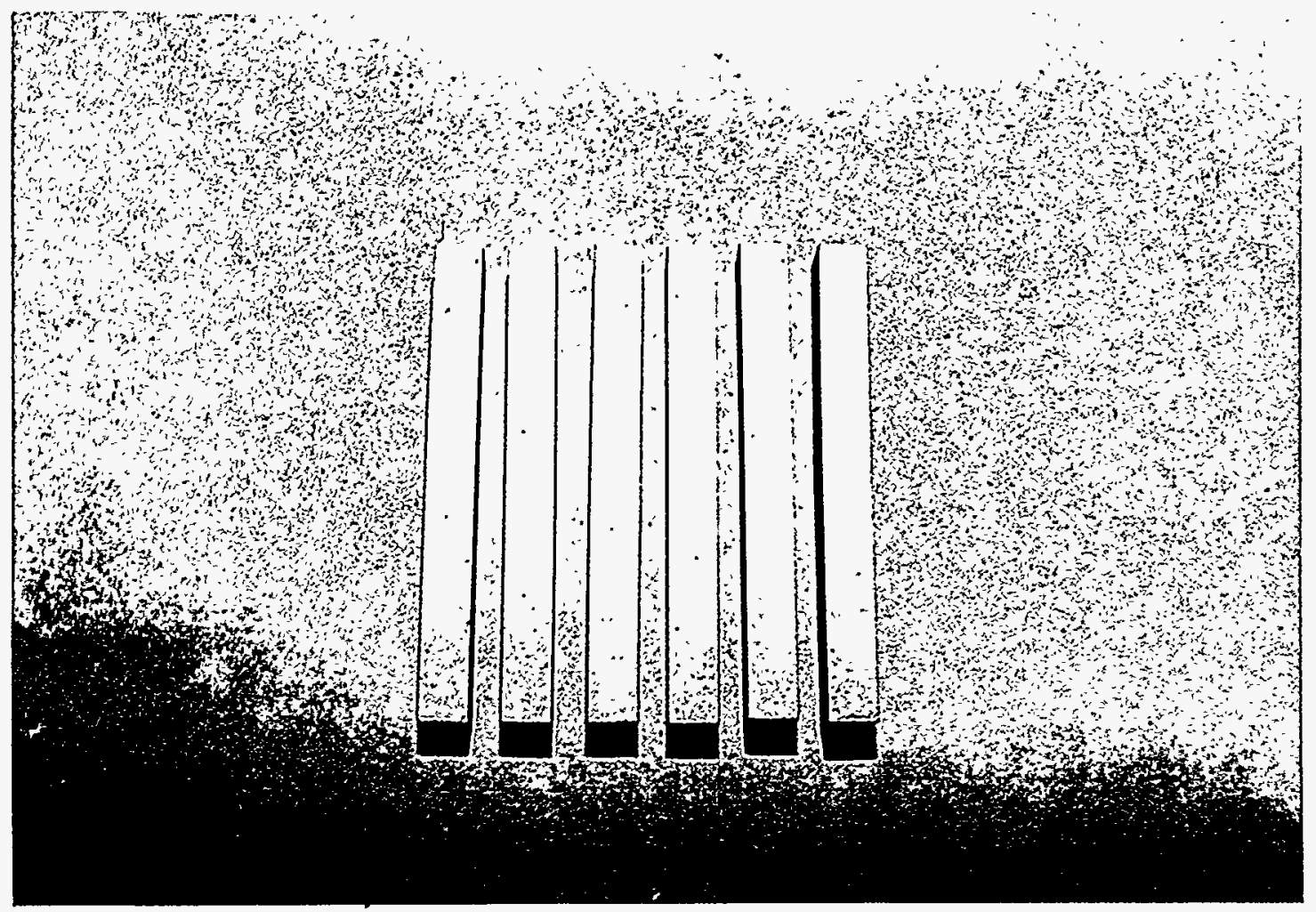

Figure 3. Dry pressed bars prepared from unquenched material 


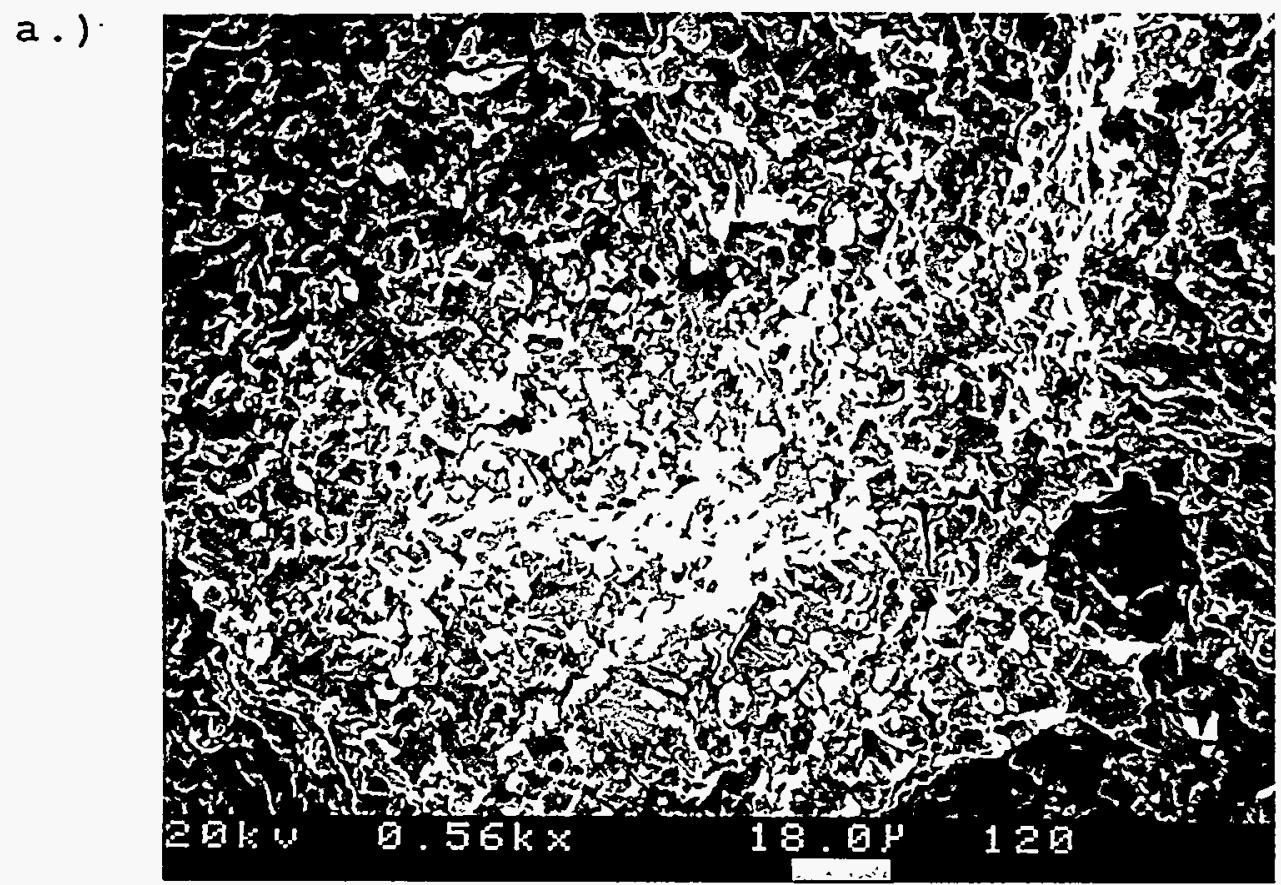

b.)

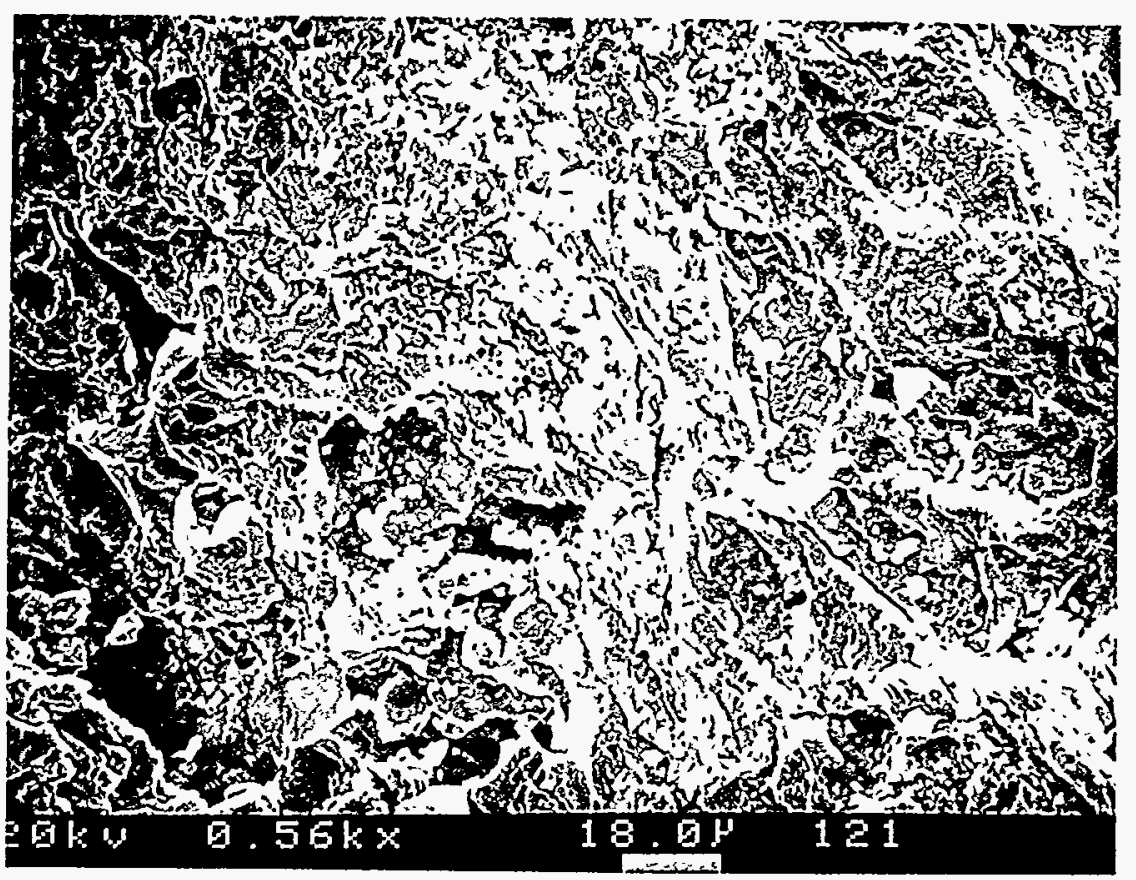

Figure 4. SEM micrographs of a.) bars made from quenched material versus b.) bars made from unquenched material 